\title{
Clinical Characteristics of Children Admitted to the Pediatric Emergency Department Referred from Outpatient Departments
} Ying-Ju Chen ${ }^{1 \dagger}$, Chun-Yu Chen ${ }^{1,2+}$,Wen-Chieh Yang ${ }^{1,2}$ and Han-Ping $\mathrm{Wu}^{1,2,3^{*}}$

${ }^{1}$ Department of Pediatric Emergency Medicine, Children Hospital, China Medical University, Taichung, Taiwan

${ }^{2}$ Department of Medicine, School of Medicine, China Medical University, Taichung, Taiwan

${ }^{3}$ Department of Medical Research, Children's Hospital, China Medical University, Taichung, Taiwan

\section{Abstract}

Objective: The objective of this study was to describe characteristics of children referred from our outpatient department (OPD) to the pediatric emergency department (PED).

Method: All pediatric patient charts from October 2018 to January 2020 who were referred from our OPD to PED were reviewed. The following clinical information was studied: demographics, (age, gender, distribution of patients by month) diagnosis, and disposition (admission, discharge).

Results: During the 16-month study period, 867 patients were enrolled, 468 (54\%) were discharged from PED, and 399 (46\%) were admitted. In this study, 654 (75.4\%) of the 867 children were aged $<6$ years. The three most common referred divisions of OPDs were division of pediatric gastroenterology $(412, \mathrm{P}=$ $0.000)$, division of pediatric infectious disease $(182, \mathrm{P}=0.784)$, and division of pediatric neurology $(99, \mathrm{P}$ $=0.000)$.

Conclusion: In this single-hospital study, children referred from OPDs to PED were more likely to be discharged from PED than admitted to the hospital. We suggest that effective communication with parents and well clinical evaluation may reduce unnecessary emergency resource use and inpatient admissions.

\section{Publication History:}

Received: March 11, 2020

Accepted: April 06, 2020

Published: April 08, 2020

\section{Keywords:}

OPD, PED, Emergency medical care, Diagnosis, Database

\section{Introduction}

Many studies have pointed out that the use of emergency medical care in children was mostly not urgent, and it is estimated that $59 \%$ of children's emergency medical use abroad was considered non-urgent [1-4]. The inappropriate use of emergency medical care may appear as a global problem. In the United States, children account for about $25 \%$ of all emergency medical use. Emergency department (ED) crowding threatens patient safety, increases medical judgment errors, prolongs hospital stays, reduces patient satisfaction, and jeopardizes the reliability and ability of healthcare system to effectively care for patients [5-7]. Previous studies reported that the quality of timeliness and effectiveness indicators showed a correlation between visits for pediatric patients with acute asthma attacks in the ED showed an negative correlation with the amounts of patient visits [8-10]. In this study, we aimed to survey describe characteristics of children referred from our outpatient department (OPD) to the pediatric ED for further survey the medical quality of PED and reduce unnecessary resource use.

\section{Materials and Methods}

This was a retrospective study of pediatric patients aged 18 years or younger who referred from the OPD to the ED between October 2018 and January 2020. The following information was obtained from the medical records of each patient: demographics, (age, gender, distribution of patients by month) diagnosis, and disposition (admission, discharge). The primary outcomes of interest in this study were the percentage of children who required admission for further caure, and discharged home after referring to the PED with no additional medical or surgical procedures. The data were collected, reviewed, de-identified, and anonymously analyzed by the authors, and the Ethics Committee waived the requirement for informed consent because of the anonymized nature of the data, and scientific purpose of the study.

This OPD was defined as the divisions of the pediatric subspecialties, including pediatric gastroenterology, pediatric cardiology, pediatric hematology, pediatric neurology, pediatric metabolism \& endocrinology, pediatric chest, pediatric nephrology, pediatric surgery, pediatric infectious diseases, pediatric allergy, immunology and rheumatology, and others $[3,4,11]$. In addition, the International Disease Classification Number One (ACODE ICD 10) field in the emergency file $(C D)$ of the health insurance database was used. The diagnosis was divided into the 12 groups based on the diagnostic classification used by many domestic researchers [12-13]. If children received more than one diagnosis, a primary diagnosis was assigned in the following order: respiratory disease (croup, pneumonia, bronchitis, bronchiolitis, acute otitis media and acute laryngitis), gastrointestinal diseases (gastritis, colitis, hepatitis and pancreatitis) and infectious disease (enterovirus infection, influenza and fever). Data of distributions of variables were reported as percentages and means \pm standard deviation (SD). the frequency distribution, percentage, and average are used to describe the emergency medical use of children.

\section{Results}

During the 16-month study period, 867 pediatric patients (456 boys and 411 girls) admitted to the pediatric ED referred from the OPD were enrolled in our study. The mean age was $4.5 \pm 0.05$ in boys, and $4.1 \pm 0.05$ in girls. In addition, $654(75.4 \%)$ of the 867 children

"Corresponding Author: Prof. Han-Ping Wu, Department of Medical Research, Department of Pediatric Emergency Medicine, Children's Hospital, China Medical University, Taichung, Taiwan. No. 2, Yuh-Der Road, Taichung 404, Taiwan, Tel: +886-4-22052121; E-mail: arthur1226@gmail.com

+Ying-Ju Chen and Chun-Yu Chen contributed equally to this work.

Citation: Chen YJ, Chen CY, Yang WC, Wu HP (2020) Systematic Preoperative Complementary Tests in Elective Minor and Medium Pediatric Surgery: Is it Time to Revalue? Int J Pediatr Neonat Care 6: 163. doi: https://doi.org/10.15344/2455$2364 / 2020 / 163$

Copyright: ( 2020 Chen et al. This is an open-access article distributed under the terms of the Creative Commons Attribution License, which permits unrestricted use, distribution, and reproduction in any medium, provided the original author and source are credited. 
Citation: Gafsi B, Toumi S, Zouaoui A, Moula K, Ksia A, et al. (2020) Systematic Preoperative Complementary Tests in Elective Minor and Medium Pediatric Surgery: Is it Time to Revalue? Int J Pediatr Neonat Care 6: 162. doi: https://doi.org/10.15344/2455-2364/2020/162

Page 2 of 4

were aged under 6 years (Table 1). The most common age group of children referred from the OPD was preschool age, followed by school age group. Male to female ratio of children who referred from the OPD to the PED was 1.1:1, and about $60 \%$ of them were within the age between 2-6 years old. The distribution of the triage system in the patients presented to the ED was recorded and shown as below: $7(0.8 \%)$ at level $1,222(25.6 \%)$ at level 2, $619(71.4 \%)$ at level 3, 19 $(2.2 \%)$ at level 4 , and no referral at level 5. The most common level of triage for the pediatrics referred from the OPD was level 3 while level 1 and level 5 were quite low. The most common seasons was summer, followed by winter.

The 3 most common divisions referral from the OPD were pediatric gastroenterology, pediatric infectious diseases, and pediatric neurology $(47.5 \%, 21 \%$, and $11.4 \%$, respectively) (Figure 1$)$. The rate of discharge from $\mathrm{ED}$ was $54 \%$, and 399 cases required admission for further care (46\%). The 3 most common diseases at presentation in the ED were gastrointestinal diseases, respiratory diseases and infectious diseases (32.9\%, 26.8\%, and $25.4 \%$, respectively). The most common diagnosis requiring admission was respiratory diseases, followed by infectious diseases; while the most common diagnosis of pediatric patients who could be discharged home later was gastrointestinal diseases, followed by infectious diseases (Figure 2). The 2 most common referral months were July and August ( $\mathrm{n}=95 ; \mathrm{n}=88$, respectively) (Figure 3 ).

\section{Discussion}

In our study, we found about $60 \%$ of them were within the age between 2-6 years old. In the previous studies, children between the ages of 1 and 6 started to have group life in kindergartens, so they were more likely to infect with each other and required more medical service than those in other age groups. In our study, we found the common season in children referred from the OPD to ED was summer such as in July and August, followed by winter. This result may differ from some physicians' clinical experience. It is not only the outbreak of infectious diseases, such as enterovirus infection or bacterial colitis, but we usually arrange specific examinations and elective surgery during our summer vacation (July and August). This may provide emergency physicians more information for understanding the possible infectious etiologies and epidemiological issues in the seasons. Diagnoses of children admitted to ED for observation may

\begin{tabular}{|c|c|c|}
\hline \multicolumn{3}{|r|}{ Values are $\mathrm{n}(\%)$} \\
\hline & \begin{tabular}{|l} 
Male \\
$(\mathrm{n}=456)$ \\
$\mathrm{n},(\%)$
\end{tabular} & $\begin{array}{l}\begin{array}{l}\text { Female } \\
(\mathrm{n}=411) \\
\mathrm{n},(\%)\end{array} \\
\end{array}$ \\
\hline Age, years & $4.5 \pm 0.05$ & $4.1 \pm 0.05$ \\
\hline \multicolumn{3}{|l|}{ Classification of age } \\
\hline $0-1$ (infant) & 67 (14.7) & $69(16.8)$ \\
\hline 2-6 (preschool) & $272(59.6)$ & $246(59.9)$ \\
\hline 7-12 (primary school) & $81(17.8)$ & $69(16.8)$ \\
\hline 13-18 (middle or high school) & $36(7.9)$ & $27(6.6)$ \\
\hline \multicolumn{3}{|l|}{ Season of referral } \\
\hline Spring & $84(18.4)$ & $76(18.5)$ \\
\hline Summer & $131(28.7)$ & $114(27.8)$ \\
\hline Fall & $130(28.5)$ & $69(16.8)$ \\
\hline Winter & $111(24.3)$ & $104(25.3)$ \\
\hline \multicolumn{3}{|l|}{ Triage } \\
\hline Level 1 & $5(1.1)$ & $2(0.5)$ \\
\hline Level 2 & $116(25.4)$ & $106(25.8)$ \\
\hline Level 3 & $323(70.8)$ & $296(72.0)$ \\
\hline Level 4 & $12(2.6)$ & $7(1.7)$ \\
\hline Level 5 & $0(0)$ & $0(0)$ \\
\hline \multicolumn{3}{|c|}{ Diagnosis of discharge based on the divisions } \\
\hline Pediatric Cardiology & $10(1.2)$ & $4(0.5)$ \\
\hline Pediatric Surgery & $2(0.2)$ & $1(0.1)$ \\
\hline Pediatric Hematology & $3(0.3)$ & $2(0.2)$ \\
\hline Pediatric Neurology & $10(1.2)$ & $9(1.0)$ \\
\hline Neurosurgery & $1(0.1)$ & $1(0.1)$ \\
\hline Pediatric Thoracic Medicine & $129(14.9)$ & $103(11.9)$ \\
\hline Pediatric Nephrology & $21(2.4)$ & $33(3.8)$ \\
\hline Pediatric Infectious Diseases & $114(13.2)$ & $106(12.2)$ \\
\hline Pediatric Endocrinology & $2(0.2)$ & $0(0)$ \\
\hline Pediatric Gastroenterology & $149(17.2)$ & $136(15.7)$ \\
\hline Pediatric A.I.R. & $12(1.4)$ & $10(1.2)$ \\
\hline Other & $3(0.3)$ & $6(0.7)$ \\
\hline Hospitalization amount & $216(47.4)$ & $183(44.5)$ \\
\hline Discharge amount & $240(52.6)$ & $228(55.5)$ \\
\hline
\end{tabular}

Table 1: General demographics of patients.

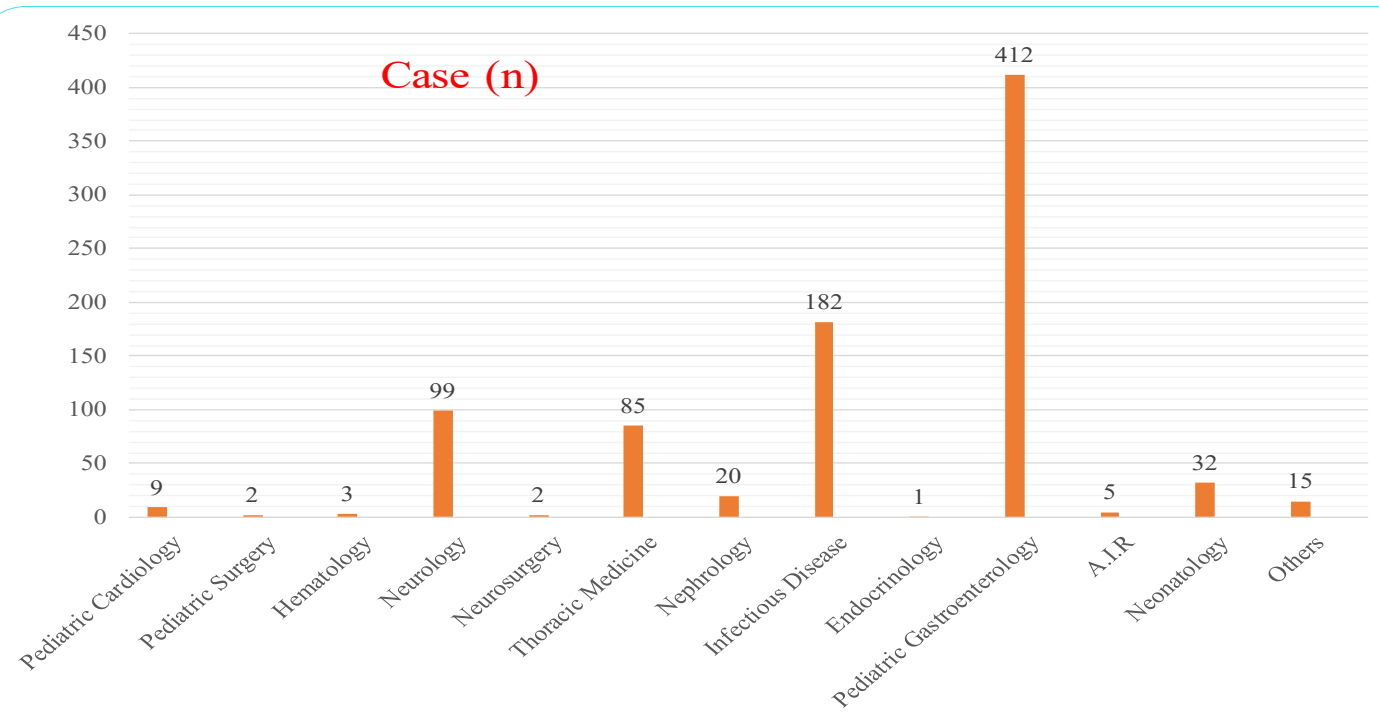

Figure 1: Case distribution referred to the outpatient department.

(A.I.R.: Allergy, Immunology, Rheumatology) 
Citation: Gafsi B, Toumi S, Zouaoui A, Moula K, Ksia A, et al. (2020) Systematic Preoperative Complementary Tests in Elective Minor and Medium Pediatric Surgery: Is it Time to Revalue? Int J Pediatr Neonat Care 6: 162. doi: https://doi.org/10.15344/2455-2364/2020/162

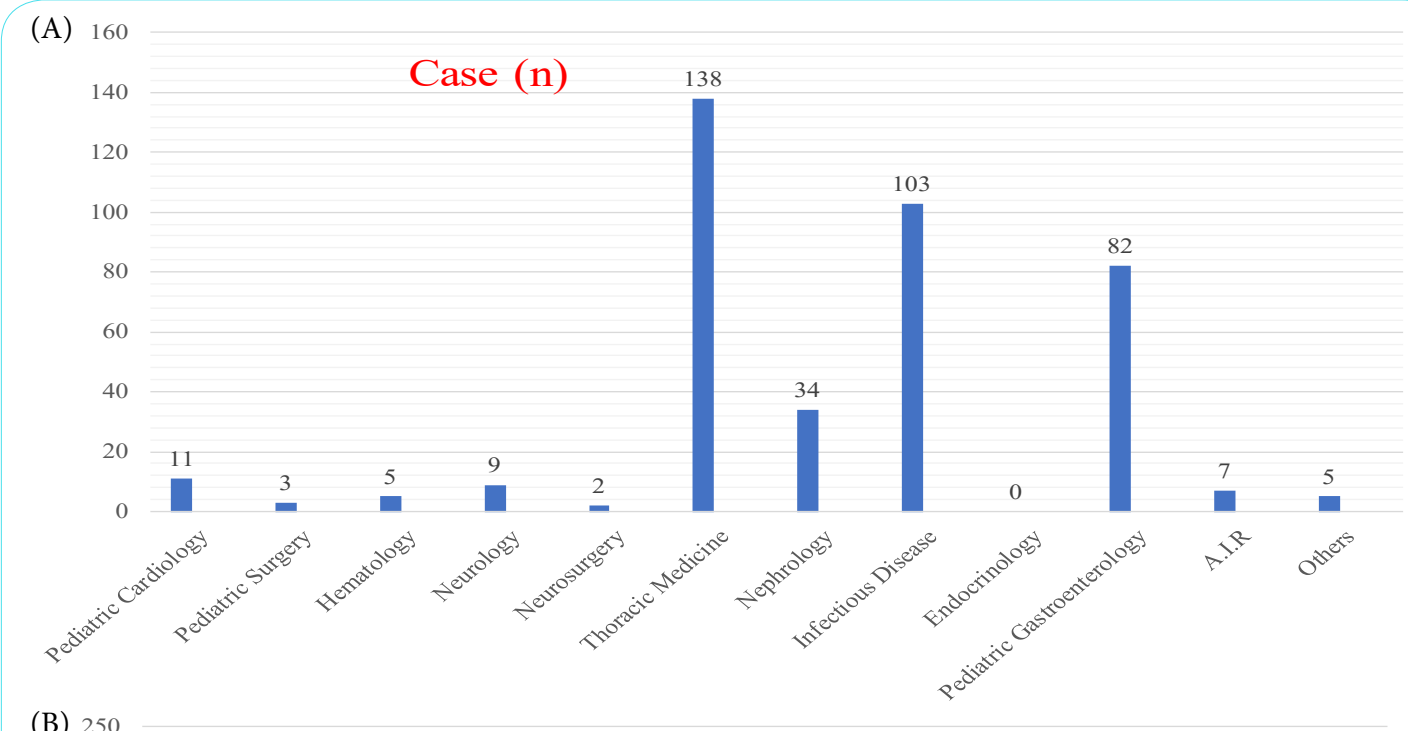

(B) 250

Case (n)

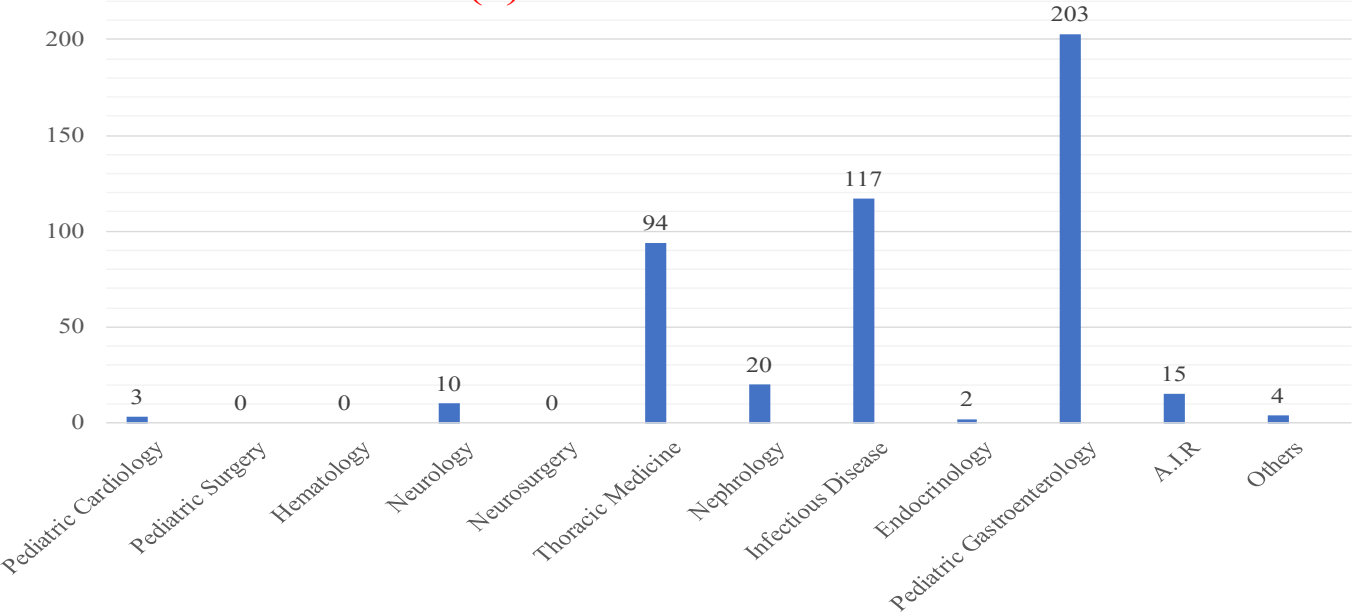

Figure 2: (A) Total amounts of hospital admission from the outpatient department- referred cases, (B) Total amounts of hospital discharges from the outpatient department- referred cases.




Citation: Gafsi B, Toumi S, Zouaoui A, Moula K, Ksia A, et al. (2020) Systematic Preoperative Complementary Tests in Elective Minor and Medium Pediatric Surgery: Is it Time to Revalue? Int J Pediatr Neonat Care 6: 162. doi: https://doi.org/10.15344/2455-2364/2020/162

Page 4 of 4

vary based on different countries; however, pediatric gastrointestinal diseases were one of the most frequent diseases requiring pediatric emergency care and further observation in the previous studies [1416]. It was similar to our results, the most common referral division of OPD was the pediatric gastroenterology, and the most common diagnosis at presentation was gastrointestinal diseases, especially in referred children discharged home from ED without admission. However, in patients requiring admission to the wards, the most common diagnosis was respiratory diseases. Therefore, once children are referred from the OPD due to respiratory problems, primary physicians should pay more attention to them due to the high possibility of admission for further care.

More than half of the pediatric patients referred from the OPD to the pediatric ED may not need to admit to the ward, and even more than one-third of them could not need further blood laboratory tests or intravenous fluid infusion. It may indicate that detailed clinical history taking and physical examinations should be enough and important for clinicians to evaluate and manage children in the OPD before deciding to refer to ED. Moreover, in Taiwan, children's medical treatment is very convenient, and the implementation of universal health insurance lead to reduce the barriers for children to use medical care, resulting in high utilization of emergency care [17].

Finally, the results of this study represented a single ED situation of a medical center, and the situation may be different in other hospitals. It is necessary to have further survey in other EDs to realize the quality of emergency medical use for children. In conclusion, in this singlehospital study, children referred from the OPD to ED were more likely to be discharged home from ED than admission to the ward. Certain pediatric illnesses, such as gastrointestinal diseases, appear to be well managed during the short-term pediatric emergency room visit or observation unit stay. We suggest effective communication with parents and well clinical evaluation may prevent unnecessary emergency resource use and inpatient admissions.

\section{Competing Interests}

The authors declare that they have no competing interests.

\section{References}

1. Brousseau DC, Gorelick MH, Hoffmann RG, Flores G, Nattinger AB (2009) Primary care quality and subsequent emergency department utilization for children in Wisconsin Medicaid. Acad Pediatr 9: 33-39.

2. Hu SC, Yen DHT, Kao WF (2001) Demographics and quality assurance in an emergency department in a medical center in eastern Taiwan. Tzu Chi Med J 13: 223- 229.

3. Garcia TC, Bernstein AB, Bush MA (2010) Emergency department visitors and visits: who used the emerg ency room in 2007. NCHS Data Brief 38: 1-8.

4. Hunt KA, Weber EJ, Showstack JA, Colby DC, Callaham ML (2006) Characteristics of frequent users of emergency departments. Ann Emerg Med 48: 1- 8

5. Institute of Medicine. Hospital-Based emergency care: At the Breaking Point. Washington, DC: National Academies Press, 2006.

6. Niska R, Bhuiya F, Xu J (2010) National Hospital Ambulatory Medical Care Survey: 2007 Emergency Department Summary. Natl Health Stat Report 6 $1-31$.

7. Nourjah P (1999) National Hospital Ambulatory Medical Care Survey: 1997 Emergency Department Summary. Adv Data 6: 1-24.

8. Li G, Lau JT, McCarthy ML, Schull MJ, Vermeulen M, Kelen GD (2007) Emergency department utilization in the United States and Ontario, Canada. Acad Emerg Med 14: 582-584.

9. Gardner RL, Sarkar U, Maselli JH, Gonzales R (2007) Factors associated with longer ED lengths of stay. Am J Emerg Med 25: 643-650.
10. Shah MN, Cushman JT, Davis CO, Bazarian JJ, Auinger P, et al. (2008) The epidemiology of emergency medical services use by children: an analysis of the national hospital ambulatory medical care survey. Prehosp Emerg Care 12: 269-276.

11. Huang JA, Lai CS, Hu JS (2006) Relationship of utilization of emergency medical services and other medical services. Taiwan J Public Health 25: 384393.

12. Chou HK, Chang I C, Hwang H G, Tsai M T, Woung LC, et al. (2007) Apply basket analysis to explore characteristic of patients stayed emergency department over 24 hours. J Healthc Manag 8: 216-231.

13. Tseng PC, Hu PM, Liao HC, Huang CL, Liaw SJ (2009) Exploration of emergency department visits with nonspecific signs and symptoms: a population-based descriptive study. J Taiwan Coll Emerg Physician 1:22-28.

14. Numa A, Oberklaid F (1991) Can short hospital admissions be avoided? A review of admissions of less than 24 hours' duration in a pediatric teaching hospital. Med J Aust 155: 395-398.

15. Derinöz O, Tunaoğlu FS (2007) Usage of pediatric emergency department observation unit for children: observations in a university hospital. Turk Arch Ped 42: 61-64.

16. Dawson KP, Mogridge N, Abbott GD (1991) A pediatric day unit: the first year's experience. NZ Med J 104: 185-187.

17. Owens PL, Zodet MW, Berdahl T, Dougherty D, McCormick MC, et al. (2008) Annual report on health care for children and youth in the United States: focus on injury-related emergency department utilization and expenditures. Ambul Pediatr 8: 219-240.

18. Chen SH, Hu PM, Liao HC, Liaw SJ (2009) Emergency patient disposition in Taiwan: a population-based descriptive study. J Taiwan Coll Emerg Physician 1: 11-21. 